\title{
Pulmonary Rehabilitation in COPD: Effect of 2 Aerobic Exercise Intensities on Subject-Centered Outcomes-A Randomized Controlled Trial
}

\author{
Catarina Santos PT MSc, Fátima Rodrigues MD MSc, Joana Santos PT, Luísa Morais PT, and \\ Cristina Bárbara MD PhD
}

\begin{abstract}
BACKGROUND: Exercise training is an important component of pulmonary rehabilitation, but it remains questionable how training intensity affects patient-centered outcomes. The aim of this study was to compare the effects of 2 aerobic training intensities on health-related quality of life (HRQOL), symptom control, and exercise tolerance in subjects with COPD. METHODS: Thirtyfour subjects with mild to very severe COPD participated in an equivalence/non-inferiority randomized controlled trial with a parallel group blinded to 60 or $80 \%$ maximum work rate $\left(W_{\max }\right)$ aerobic training intensity. The intervention was an out-patient pulmonary rehabilitation program conducted 3 times/week for 8 weeks. Outcomes were assessed with the St George Respiratory Questionnaire (primary outcome), Mahler's dyspnea index, London Chest Activity of Daily Living scale, 6-min walk test, and constant-load and incremental exercise tests. RESULTS: Subjects were randomly allocated to aerobic training intensity of $60 \% \mathrm{~W}_{\max }$ (group $1, n=17$ ) or $80 \% \mathrm{~W}_{\text {max }}$ (group 2, $n=17$ ). Although there were significant improvements in all outcomes for both groups, there were no between-group differences in mean change in the St George Respiratory Questionnaire $(P=.31,95 \% \mathrm{CI}-12.0$ to 3.9), Mahler's dyspnea index $(P=.38)$, London Chest Activity of Daily Living scale $(P=.92), 6$-min walk test $(P=.50,95 \%$ CI 6.2-71.1), constant-load exercise test $(P=.50)$, and incremental exercise test $(P=.12)$. There was only one exercise-related adverse event of cardiac symptoms. CONCLUSIONS: Aerobic training intensity of at least $60 \% \mathrm{~W}_{\text {max }}$ has a positive impact on COPD patient-centered outcomes, with no additional benefit of increasing intensity to $80 \% \mathrm{~W}_{\text {max }}$ in HRQOL, symptom control, and exercise tolerance, challenging the present clinical attitude of rehabilitation professionals. (ClinicalTrials.gov registration NCT01944072.) Key words: COPD; rehabilitation; exercise intensity; aerobic training; health-related quality of life. [Respir Care 2015;60(11):1603-1609. (c) 2015 Daedalus Enterprises]
\end{abstract}

\section{Introduction}

COPD is the world's fourth leading cause of mortality ${ }^{1}$ and is projected in 2020 to be the fifth leading disease in

Ms C Santos is affiliated with Fisioterapia, Centro Hospitalar de Lisboa Ocidental-Hospital de Egas Moniz, Lisbon, Portugal. Ms Rodrigues is affiliated with the Serviço de Pneumologia, Centro Hospitalar Lisboa Norte (CHLN)-Hospital Pulido Valente, and NOVA Medical School /Faculdade de Ciências Médicas, Universidade Nova de Lisboa, Lisbon, Portugal. Ms J Santos and Ms Morais are affiliated with the Unidade de Reabilitação Respiratória, Serviço de Pneumologia, CHLNHospital Pulido Valente, Lisbon, Portugal. Ms Bárbara is affiliated with Serviço de Pneumologia, CHLN-Hospital Pulido Valente, and the Faculdade de morbidity impact. ${ }^{2}$ Exercise intolerance in these patients is multifactorial and explained by several known mechanisms. $^{3-5}$ The Global Initiative for Chronic Obstructive Lung Disease (GOLD) recommends, with level A evidence, pulmonary rehabilitation programs to all symptom-

\footnotetext{
Medicina da Universidade de Lisboa, Instituto de Saúde Ambiental (ISAMB), Lisbon, Portugal.

The authors have disclosed no conflicts of interest.

Correspondence: Catarina Santos PT MSc, Rua Maria Judite de Carvalho, 15-7A, 2810-409 Almada, Portugal. E-mail: fisiocsantos@gmail.com.
}

DOI: $10.4187 /$ respcare.03663 
atic patients with COPD. ${ }^{6}$ Although this exercise-based treatment is scientifically established in published guidelines, ${ }^{7-12}$ there is a wide range of studies presenting diverse exercise-training methodologies in clinical practice. ${ }^{13,14}$ Aerobic exercise training is recommended 3-5 times/week for at least 20 sessions of $30-90 \mathrm{~min}$ at $60-80 \%$ maximum work rate $\left(\mathrm{W}_{\max }\right)$ of continuous or intermittent use of a treadmill, bicycle, step, elliptic, or rowing machine. ${ }^{7,15,16}$ Current investigation has not yet identified the critical exercise intensity, ${ }^{17}$ but it is established that physiological benefits are achieved with a minimum of $60 \% \mathrm{~W}_{\max }$ and that the higher the intensities, the greater the physiological benefits. ${ }^{10,13,18}$ Furthermore, it has not been proven conclusively that these physiological benefits would lead to greater improvements in patientcentered outcomes.7,15,16 Current patient-centered outcomes provide the strongest evidence of the impact of pulmonary rehabilitation programs on patients with COPD $^{19}$ by measuring improvement in symptoms, exercise performance, and quality of life, which are the most meaningful changes for the patient. Considering the intensity range recommended by international guidelines of $60-$ $80 \% \mathrm{~W}_{\max }$, we do not know whether higher intensities achieve the best impact on patient-centered outcomes. For this purpose, we tested the hypothesis that 2 aerobic training intensities $\left(60\right.$ and $80 \% \mathrm{~W}_{\max }$ ) had equal or non-inferior effects on COPD patient-centered outcomes: healthrelated quality of life (HRQOL), symptom control, and exercise tolerance.

\section{Methods}

This was an equivalence/non-inferiority trial with blocked stratified randomization of subject-blinded assignment in a parallel group design, with an allocation ratio of $1: 1$. Eligible participants were stable subjects with COPD, with $\mathrm{FEV}_{1} / \mathrm{FVC}<0.70$, recruited by medical referral for exercise training. Exclusion criteria were inability to attend a program 3 times/week; metastatic neoplasia; infectious or unstable cardiac diseases; and neuromusculoskeletal, psychiatric, or cognitive disorders. The trial was conducted between January 2009 and March 2010 at the Hospital Pulido Valente in Lisbon, Portugal, with an experienced pulmonary rehabilitation program, which serves 350,000 inhabitants. The hospital's ethics committee and administrative board approved the trial conduction (institutional review board DIRCLIN-07.ABR.2009-0256), and all subjects gave written informed consent. The trial is registered as NCT01944072.

The intervention consisted of a 20-session out-patient pulmonary rehabilitation program of therapeutic exercise (aerobic, strength, and flexibility) plus education and skills training. Aerobic exercise was $30 \mathrm{~min}$ of training 3 times/ week on a treadmill (Light Commercial Europe, Mercury

\section{QUICK LOOK}

\section{Current knowledge}

COPD is the world's fourth leading cause of mortality and is projected to be the fifth leading disease in morbidity impact by 2020 . Exercise intolerance in these patients is associated with both worsening morbidity and mortality. Pulmonary rehabilitation including exercise training has met with mixed results in improving quality of life and symptoms. The optimum intensity of exercise during rehabilitation is frequently debated.

\section{What this paper contributes to our knowledge}

During pulmonary rehabilitation, aerobic training intensity of at least $60 \%$ maximum work rate $\left(\mathrm{W}_{\max }\right)$ had a positive impact in COPD subject-centered outcomes, with no additional benefit of increasing intensity to $80 \% \mathrm{~W}_{\max }$ in health-related quality of life, symptom control, and exercise tolerance. Work intensity needs to be sufficient to provide benefit without resulting in exercise intolerance.

BH, Vitoria-Gasteiz, Spain) or bicycle (Erg602BE, Dimeq, Berlin, Germany) according to subjects' preference, with an intensity of $60 \% \mathrm{~W}_{\max }$ (group 1) or $80 \% \mathrm{~W}_{\max }$ (group 2) of an initial incremental exercise test. ${ }^{3}$ Strength training was combined 2 times/week with multi-station equipment (CybexMG500 Multi-Gym, Cybex, Medway, MA) in 3 sets of 8 repetitions at $50 \%$ of one-repetition maximum for selected exercises (seated leg press, seated calf raise, seated row, abdominal crunch, and chest press). Flexibility training was combined 3 times/week with $5 \mathrm{~s}$ of stretching for each of 7 selected large body muscle exercises. There were 5 education and skills training group-oriented sessions: COPD, medication and respiratory devices, breathing exercises, bronchial hygiene techniques, and benefits of physical exercise. HRQOL was the primary outcome measured by the St George Respiratory Questionnaire (SGRQ), ${ }^{20}$ with a score ranging from 0 to 100 , with higher scores meaning worse HRQOL. Secondary outcomes were symptom control measured by Mahler's dyspnea index ${ }^{21}$ (scores ranging from -9 to +9 , with positive scores meaning improvement in dyspnea) and by the London Chest Activity of Daily Living (LCADL) scale 22 (scores ranging from 0 to 75, with higher scores meaning more limitations on activities of daily living) and exercise tolerance assessed by a 6-min walk test (6MWT) ${ }^{23}$ (functional capacity), incremental exercise test ${ }^{3}$ (peak aerobic capacity), and constant-load exercise test ${ }^{3}$ (endurance capacity). The minimum clinically important differences were: \pm 4 for the SGRQ, ${ }^{24,25} 1$ point for the transitional dyspnea index, ${ }^{24-26} 25 \mathrm{~m}$ for the 6-min walk distance (6MWD), ${ }^{27}$ 
and $100 \mathrm{~s}$ for the constant-load exercise test. ${ }^{28,29}$ The incremental exercise and constant-load exercise tests were assessed before and after the pulmonary rehabilitation program; all other outcomes were also accessed at the tenth session for intention-to-treat analysis. Considering the primary outcome, 34 subjects were studied for a clinically important target difference of 12 points in the SGRQ ${ }^{24,25}$ between intervention groups (group 1, $n=17$; group 2, $n=17$ ). This sample size was statistically calculated using the PS: Power and Sample Size Calculation program (Vanderbilt University, Nashville, Tennessee), with 5\% significance level, a power of $80 \%$, an SGRQ SD of 11.33 points, ${ }^{30}$ and a $10 \%$ predicted dropout rate. A subject's allocation sequence was computer-generated, and the randomization was stratified by a cutoff value of $0.50 \mathrm{FEV}_{1}$, with an allocation ratio of $1: 1$ using random block sizes of 2 (mild to moderate COPD, severe to very severe COPD). The research physiotherapist assessed eligibility, discussed the trial, and obtained informed consent from the subject. Another physiotherapist adapted the subject to the treadmill or bicycle, and only after the chest physician assessed the subject by an incremental exercise test was an allocation consignment given according to a schedule maintained in a safe deposit box. This was a subject-blinded study, as all subjects participated in the same pulmonary rehabilitation program with individualized aerobic intensity training from the incremental exercise test but could not differentiate who was training at 60 or $80 \% \mathrm{~W}_{\max }$. Blinding was not applied to health-care providers due to their role in monitoring intensity targets of aerobic training. Statistical analysis was conducted with PASW Statistics 18.0.0 (SPSS, Chicago, Illinois), with a modified intention-totreat analysis considering a minimum of 10 sessions of attendance of the pulmonary rehabilitation program. Primary outcome was change in the SGRQ, with the total and impact scores analyzed with the Satterthwaite test (normal distribution and unequal variances) and activity and symptom scores analyzed with the Student $t$ test (normal distribution and equal variances). Secondary outcomes were change in the transitional dyspnea index, LCADL scale, incremental exercise test, and constant-load exercise test (analyzed by the Mann-Whitney $U$ test, non-normal distribution) and change in 6MWD (analyzed by the Student $t$ test, normal distribution and equal variances). All outcomes were also analyzed for inferential statistics with the Pearson coefficient (continuous variable) except for the transitional dyspnea index and LCADL scale, which were analyzed with the Spearman coefficient (ordinal variable).

\section{Results}

As shown in Figure 1, a total of 56 subjects were recruited between January and December of 2009, with 22

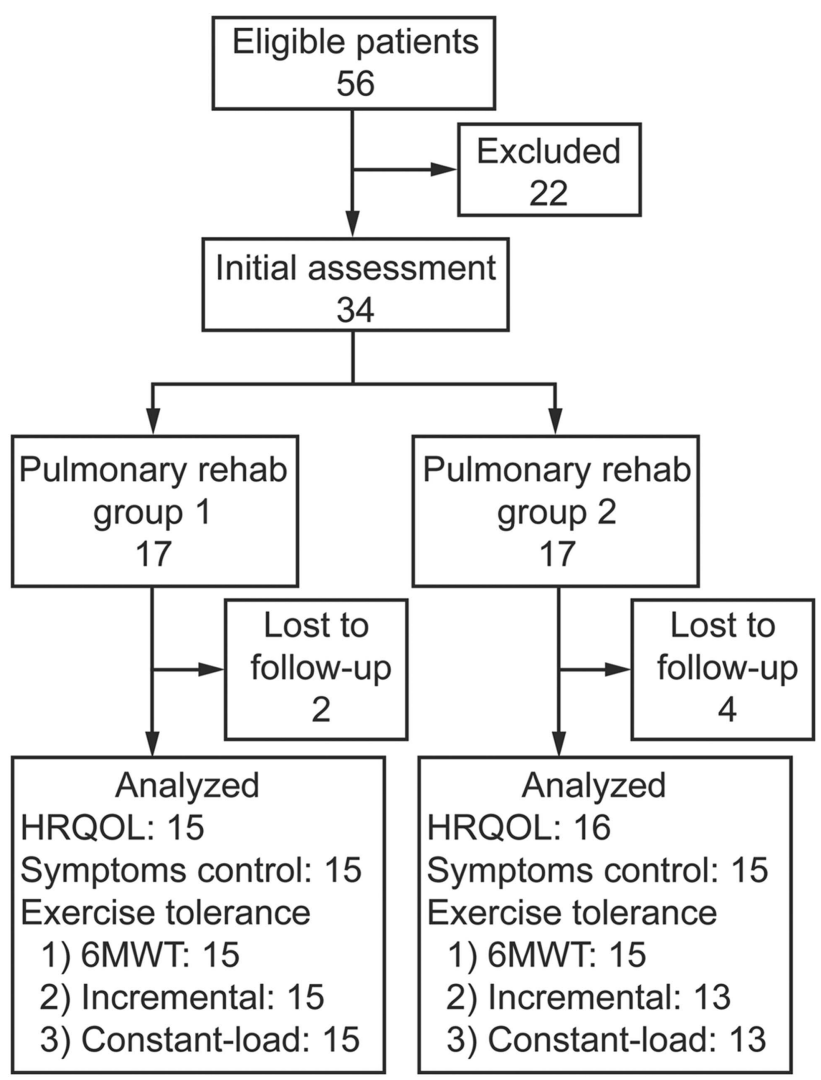

Fig. 1. Flow chart. $\mathrm{HRQOL}=$ health-related quality of life. $6 \mathrm{MWT}=6$-min walk test.

excluded, and the trial was stopped when the sample size goal was achieved $(n=34)$. The intervention phase was February 2009 to March 2010. Table 1 presents subjects' baseline demographic and clinical characteristics. The 20session pulmonary rehabilitation program had a mean duration of $8.2 \pm 1.8$ weeks for group 1 and $7.9 \pm 2.9$ weeks for group 2.

For the purpose of analysis, treadmill and bicycle intensity units were converted to metabolic equivalents by American College of Sports Medicine formulas. ${ }^{31}$ The mean intensity of the aerobic exercise training was $4.3 \pm 0.9$ metabolic equivalents for group 1 and $5.5 \pm 1.8$ metabolic equivalents for group 2, which correspond to an overall mean efficiency of aerobic training intensity exercised/ prescribed of $87.1 \%$ (group $1=92 \%$, group $2=82 \%$ ). Determined by the subjects' choice, both groups were similar, considering the training modality $(76 \%$ treadmill and $24 \%$ bicycle) and the type of training (94\% continuous and $6 \%$ interval). All subjects had $100 \%$ efficiency of strength training intensity exercised/prescribed (ie, 50\% of onerepetition maximum) and attended the education and skills training group sessions as programmed.

The primary analysis was modified intention to treat with 31 of 34 subjects randomly assigned (see Fig. 1) due 
Table 1. Demographic and Clinical Baseline Data

\begin{tabular}{|c|c|c|}
\hline & $\begin{array}{l}\text { Group 1: } 60 \% \\
\mathrm{~W}_{\text {max }}(n=17)\end{array}$ & $\begin{array}{c}\text { Group 2: } 80 \% \\
\mathrm{~W}_{\text {max }}(n=17)\end{array}$ \\
\hline \multicolumn{3}{|l|}{ Sex, $n(\%)$} \\
\hline Male & $12(70.6)$ & $15(88.2)$ \\
\hline Female & $5(29.4)$ & $2(11.8)$ \\
\hline Age, mean \pm SD y & $66.9 \pm 11.4$ & $67.3 \pm 10.4$ \\
\hline \multicolumn{3}{|l|}{ Education level, $n(\%)$} \\
\hline Elementary school & $5(29.4)$ & $4(23.5)$ \\
\hline Secondary education & $9(52.9)$ & $10(58.8)$ \\
\hline Higher education & 3 (17.6) & $3(17.6)$ \\
\hline \multicolumn{3}{|l|}{ Professional activity, $n(\%)$} \\
\hline Unemployed & $1(5.9)$ & $1(5.9)$ \\
\hline Active & $3(17.6)$ & $1(5.9)$ \\
\hline Retired & $13(76.5)$ & $15(88.2)$ \\
\hline \multicolumn{3}{|l|}{ Pulmonary function, mean \pm SD } \\
\hline FVC, L & $3.0 \pm 1.0$ & $3.5 \pm 0.9$ \\
\hline FVC, $\%$ predicted & $87.8 \pm 20.3$ & $96.4 \pm 19.3$ \\
\hline $\mathrm{FEV}_{1}, \mathrm{~L}$ & $1.4 \pm 0.4$ & $1.6 \pm 0.5$ \\
\hline $\mathrm{FEV}_{1}, \%$ predicted & $54.1 \pm 15.6$ & $55.7 \pm 16.4$ \\
\hline $\mathrm{FEV}_{1} / \mathrm{FVC}$ & $0.48 \pm 0.12$ & $0.45 \pm 0.10$ \\
\hline Oxygen therapy, $n(\%)$ & $0(0.0)$ & $2(11.8)$ \\
\hline \multicolumn{3}{|l|}{ Risk factors, $n(\%)$} \\
\hline Hypertension & $10(58.8)$ & $10(58.8)$ \\
\hline Dyslipidemia & $3(17.6)$ & $2(11.8)$ \\
\hline Diabetes mellitus & $2(11.8)$ & $0(0.0)$ \\
\hline Alcoholism & $2(11.8)$ & $0(0.0)$ \\
\hline Ex-drug user & $1(5.9)$ & $1(5.9)$ \\
\hline Obesity & $1(5.9)$ & $0(0.0)$ \\
\hline \multicolumn{3}{|l|}{ Comorbidities, $n(\%)$} \\
\hline Pulmonary tuberculosis (sequelae) & $4(23.5)$ & $2(11.8)$ \\
\hline Obstructive sleep apnea syndrome & $3(17.6)$ & $1(5.9)$ \\
\hline Rhinitis/sinusitis & $3(17.6)$ & $1(5.9)$ \\
\hline Ischemic heart disease & $3(17.6)$ & $1(5.9)$ \\
\hline Benign prostatic hyperplasia & $1(5.9)$ & $3(17.6)$ \\
\hline Hypoxemic respiratory failure & $2(11.8)$ & $1(5.9)$ \\
\hline Bronchiectasis & $1(5.9)$ & $1(5.9)$ \\
\hline Gastroesophageal reflux & $1(5.9)$ & $1(5.9)$ \\
\hline Osteoporosis & $1(5.9)$ & $0(0.0)$ \\
\hline $\mathrm{W}_{\max }=$ maximum work rate & & \\
\hline
\end{tabular}

to follow-up loss of 3 subjects before the tenth session of the pulmonary rehabilitation program (respiratory infection, professional reasons, and lower-limb pain). Secondary analysis of Mahler's dyspnea index, LCADL scale, and 6MWT was carried out on 30 subjects because of the loss to follow-up of one subject (thyroid dysfunction with atrial fibrillation) at the thirteenth session of the pulmonary rehabilitation program without completing the overall assessment; the constant-load exercise and incremental exercise tests were analyzed for 28 subjects since there were a total of 6 subjects lost to follow-up (the above-mentioned 4 and another 2 due to an elective intestinal surgery and a lack of motivation).
As shown in Table 2, there was significant improvement in all outcomes, as all results exceeded the known minimum clinically important difference in both groups. Each group exceeded a 3 -fold minimum clinically important difference of 1 point in the transitional dyspnea index ${ }^{24-26}$ (almost a 4-fold minimum clinically important difference of $25 \mathrm{~m}$ in the 6MWD) ${ }^{27}$ and improved by $>100 \mathrm{~s}$ the minimum clinically important difference in the constantload exercise test, ${ }^{28,29}$ and both groups presented an improvement in the LCADL scale and incremental exercise test but without any clinical conclusion regarding its unknown minimum clinically important difference.

In primary analysis, the difference in mean changes in HRQOL between groups was not statistically significant. Although each group differed by $>4$ points in the minimum clinically important difference 24,25 in all SGRQ scores, between groups, the results fell short of the 12point effect size predefined in the trial design. In secondary analysis, the difference between groups in mean changes as an effect of aerobic training intensity of 60 or $80 \%$ $\mathrm{W}_{\max }$ in HRQOL, symptom control, and exercise tolerance was also not statistically significant.

As expected by the ancillary analysis, age was inversely correlated with the 6MWD (initial 6MWD, $\rho=-0.45$, $P=.01$; final 6MWD, $\rho=-0.53, P<.001)$ and with duration of the constant-load exercise test (initial constantload exercise test, $\rho=-0.48, P=.01$; final constant-load exercise test, $\rho=-0.62, P<.001)$. Nevertheless, there was no statistical correlation between age and improvements in the 6MWD $(\rho=0.07, P=.71)$ and constant-load exercise test $(\rho=-0.27, P=.16)$.

There were 5 adverse events during the trial, only one exercise-related, during the eleventh session of the pulmonary rehabilitation program with tachycardia, arrhythmia, and angina in a subject with heart disease history (group 1). After acute heart ischemia was excluded in the emergency room, the subject returned to the pulmonary rehabilitation program, which concluded without any other adverse events. Other adverse events not exercise-related were lower-limb pain related to lumbar hernia in one subject (group 2); gastrointestinal symptoms in 2 subjects (group 2), with one being surgically treated; thyroid dysfunction with atrial fibrillation in one subject (group 2); and respiratory infection in another one (group 1).

\section{Discussion}

In the literature, aerobic training protocols present a wide variety of types, modalities, durations, frequencies, and intensities, making a rigorous comparison of published findings difficult. This study outlined the equivalence effect of 2 aerobic training intensities on patient-centered outcomes. The main conclusion is that there were significant improvements in all outcomes for both intensities $(60$ 
Table 2. Results

\begin{tabular}{|c|c|c|c|c|}
\hline \multirow{2}{*}{ Outcome } & \multirow{2}{*}{$\begin{array}{l}\text { Group 1: } 60 \% \mathrm{~W}_{\max } \\
\quad(n=17)\end{array}$} & \multirow{2}{*}{$\begin{array}{c}\text { Group 2: } 80 \% \mathrm{~W}_{\max } \\
\quad(n=17)\end{array}$} & \multicolumn{2}{|c|}{ Effect size } \\
\hline & & & $P$ & $95 \% \mathrm{CI}$ \\
\hline \multicolumn{5}{|l|}{ HRQOL } \\
\hline \multicolumn{5}{|l|}{ Change in SGRQ, \% } \\
\hline Total & $-14.7 \pm 13.0$ & $-10.6 \pm 7.4$ & .31 & -12.0 to 3.9 \\
\hline Symptoms & $-15.7 \pm 19.2$ & $-13.5 \pm 15.0$ & .72 & -14.8 to 10.4 \\
\hline Activity & $-17.4 \pm 14.6$ & $-11.0 \pm 13.7$ & .21 & -16.8 to 4.0 \\
\hline Impact & $-12.7 \pm 16.2$ & $-9.5 \pm 7.9$ & .50 & -12.8 to 6.5 \\
\hline \multicolumn{5}{|l|}{ Symptom control } \\
\hline Change in Mahler's dyspnea index, points & $3.0 \pm 2.8$ & $3.5 \pm 3.5$ & .38 & \\
\hline Change in LCADL scale, points & $-2.3 \pm 2.5$ & $-1.5 \pm 3.5$ & .42 & \\
\hline \multicolumn{5}{|l|}{ Exercise tolerance } \\
\hline Change in $6 \mathrm{MWD}, \mathrm{m}$ & $98.9 \pm 109.0$ & $95.4 \pm 67.0$ & .92 & -64.2 to 71.1 \\
\hline Change in incremental exercise test, metabolic equivalents & $1.3 \pm 1.1$ & $1.7 \pm 0.9$ & .12 & \\
\hline Change in constant-load exercise test, s & $135.7 \pm 433.8$ & $118.0 \pm 151.1$ & .50 & \\
\hline $\begin{array}{l}\text { Data are mean } \pm \text { SD. } \\
W_{\max }=\text { maximum work rate } \\
\text { HRQOL }=\text { health-related quality of life } \\
\text { SGRQ }=\text { St George Respiratory Questionnaire } \\
\text { LCADL }=\text { London Chest Activity of Daily Living } \\
6 \mathrm{MWD}=6 \text {-min walk distance }\end{array}$ & & & & \\
\hline
\end{tabular}

and $\left.80 \% \mathrm{~W}_{\max }\right)$, but there were no differences between groups in mean changes in HRQOL, symptom control, and exercise tolerance.

\section{Effect of Aerobic Training Intensity on HRQOL}

The methodology of the pulmonary rehabilitation program with the SGRQ as an outcome is hugely diverse in the published studies, as shown by the meta-analysis of Lacasse et $\mathrm{al}^{32}$ and the systematic review of Puhan et al. ${ }^{33}$ These publications did not address the isolated effect of aerobic training intensity on patient-centered outcomes, and the evidence presented favoring high versus low intensity was weak. There is evidence of a positive effect on HRQOL, as shown by studies by Bernard et al, ${ }^{34}$ Pereira et al, ${ }^{35}$ Montes de Oca et al, ${ }^{36}$ Dourado et al, ${ }^{37}$ Arnardóttir et al, ${ }^{38}$ and Foglio et al, ${ }^{39}$, even considering the wide range of intensities in those heterogeneous pulmonary rehabilitation program interventions (type, modality, duration, and frequency). The multi-center study by Laviolette et al ${ }^{28}$ with 168 subjects with COPD also found improvement in the SGRQ after the pulmonary rehabilitation program but lacked any description of the exercise intensity applied. As far as we know, only the Normandin study ${ }^{40}$ with 40 subjects with COPD in an 8-week pulmonary rehabilitation program compared high (at least $80 \% \mathrm{~W}_{\max }$ ) with moderate intensity (calisthenics class). They found no differences between groups in HRQOL assessed by the chronic respiratory questionnaire. Our study also outlines the equivalence impact of moderate and high aerobic intensities on
HRQOL but further refines moderate intensity as $60 \%$ $\mathrm{W}_{\max }$ and high intensity as $80 \% \mathrm{~W}_{\max }$ in a comparable exercise prescription.

\section{Effect of Aerobic Training Intensity on Symptom Control}

The results of this study show that aerobic intensity of at least $60 \% \mathrm{~W}_{\max }$ has a positive impact on symptom control assessed by the transitional dyspnea index, without any superior effect of higher intensities. These findings are in accordance with the above-mentioned studies by Dourado et al, ${ }^{37}$ Foglio et al, ${ }^{39}$ and Normandin et al ${ }^{40}$ with no differences between groups.

\section{Effect of Aerobic Training Intensity on Exercise Tolerance}

International guidelines present evidence of physiological benefits associated with higher aerobic training intensities ${ }^{41}$ in accordance with historical studies by Casaburi et al, ${ }^{42}$ Maltais et al, ${ }^{43}$ Puente-Maestu et al, ${ }^{44}$ and Gimenez et al, ${ }^{45}$ but also more recently by Lacasse et al, ${ }^{32}$ Laviolette et al, ${ }^{28}$ Bernard et al, ${ }^{34}$ Montes de Oca et al, ${ }^{36}$ Dourado et al, ${ }^{37}$ Arnardóttir et al, ${ }^{38}$ Foglio et al, ${ }^{39}$ Normandin et $\mathrm{al},{ }^{40}$ and Hsieh et al. ${ }^{46}$ Those studies reported improvements in the 6MWT, incremental exercise test, and constant-load exercise test with a pulmonary rehabilitation program but without any evidence of significant differences in these outcomes as an effect of the aerobic 
training intensities applied. On the other hand, more research is needed focusing on patients' goals. ${ }^{47}$ The results of our study demonstrate that there is no superior effect of higher intensities in aerobic training on patient-centered outcomes. Therefore, different physiological effects as a result of different training intensities might have a similar impact on patients with COPD.

Overall, there were no differences between groups in mean changes in HRQOL, symptom control, and exercise tolerance as a result of aerobic training at 60 or $80 \% \mathrm{~W}_{\max }$. Perhaps the impact on patient-centered outcomes would be best achieved by designing specific training activities related to the patient's real living environment, regardless of the intensity of $\geq 60 \% \mathrm{~W}_{\max }$.

\section{Age Correlation With the 6MWT and Constant-Load Exercise Test}

According to our study, the older subjects walked shorter distances in the 6MWT and achieved shorter durations in the constant-load exercise test, both at baseline and during final assessments, but interestingly, there was no relation between age and improvement in these exercise-related outcomes. This indicates that age cannot be a predictive factor for the level of benefit from a pulmonary rehabilitation program, and this fact must be taken into account when enrolling elderly subjects.

\section{Limitations}

Among the 34 subjects studied, there were 6 adverse events, only one of them exercise-related, which did not become a loss to follow-up. Internal study validity was preserved with 31 subjects studied (group $1, n=15$; group $2, n=16$ ), in accordance with a sample size calculation of 15 subjects/group. Double or triple blinding was not applied, considering the tight exercise monitoring by physiotherapists.

The aerobic training intensity attained versus prescribed was $92 \%$ in group 1 and $82 \%$ in group 2 . The reason for this might have been the strict length of the 8-week program as defined by the protocol. Moreover, clinical practice shows that many subjects attain the target intensity with longer programs. Although it was not the purpose of our study, future research should focus on the impact of different training intensities on physical activity of daily life as a meaningful patient-centered outcome.

\section{Conclusions}

Health-care providers acknowledge the level A recommendation of a pulmonary rehabilitation program with therapeutic exercise for all symptomatic patients with COPD. This study evidenced an equivalence effect of moderate and high intensities on HRQOL, symptom control, and exercise tolerance. The implication for clinical practice is that aerobic training intensity should be at least $60 \% \mathrm{~W}_{\max }$ to achieve not only physiological benefits but also patientcentered outcomes, challenging the present clinical attitude of rehabilitation professionals. Continuing the present study, future research should address the impact of designing specific training activities related to the patient's real living environment and also the long-term effects on physical activity in daily life.

\section{REFERENCES}

1. Mathers C, Fat DM. The global burden of disease: 2004 update. World Health Organization, Geneva.

2. Respira. EFA: livro sobre a doença pulmonar obstrutiva crónica na Europa. In: Franchi M, editor. Lisbon, Portugal: Respira; Associação Portuguesa de Pessoas com DPOC e outras doenças respiratórias crónicas; 2010:132.

3. ERS Task Force, Palange P, Ward SA, Carlsen KH, Casaburi R, Gallagher CG, et al. Recommendations on the use of exercise testing in clinical practice. Eur Respir J 2007;29(1):185-209.

4. Hill NS. Pulmonary rehabilitation. Proc Am Thorac Soc 2006;3(1): 66-74.

5. Rodrigues F. [Limiting factors of exercise capacity in patients with COPD]. Rev Port Pneumol 2004;10(1):9-61. Article in Portuguese.

6. Global Initiative for Chronic Obstructive Lung Disease. Global strategy for the diagnosis, management, and prevention of chronic obstructive pulmonary disease, updated 2011. http://www.goldcopd. org/uploads/users/files/GOLD_Report_2015_Feb18.pdf.

7. American Association of Cardiovascular and Pulmonary Rehabilitation. Guidelines for pulmonary rehabilitation programs, 4th edition. Champaign, Illinois: American Association of Cardiovascular and Pulmonary Rehabilitation; 2013.

8. American Association for Respiratory Care. AARC clinical practice guideline: pulmonary rehabilitation. Respir Care 2002;37(5):617-625.

9. Ries AL. ACCP/AACVPR evidence-based guidelines for pulmonary rehabilitation. Round 3: another step forward. J Cardiopulm Rehabil Prev 2007;27(4):233-236.

10. Nici L, Donner C, Wouters E, Zuwallack R, Ambrosino N, Bourbeau $\mathrm{J}$, et al. American Thoracic Society/European Respiratory Society statement on pulmonary rehabilitation. Am J Respir Crit Care Med 2006;173(12):1390-1413.

11. Fahy BF. Pulmonary rehabilitation for chronic obstructive pulmonary disease: a scientific and political agenda. Respir Care 2004; 49(1):28-36; discussion 36-28.

12. Pierson DJ. Clinical practice guidelines for chronic obstructive pulmonary disease: a review and comparison of current resources. Respir Care 2006;51(3):277-288.

13. Gosselink R, Troosters T, Decramer M. Exercise training in COPD patients: the basic questions. Eur Respir J 1997;10(12):2884-2891.

14. Smidt N, de Vet HC, Bouter LM, Dekker J, Arendzen JH, de Bie RA, et al. Effectiveness of exercise therapy: a best-evidence summary of systematic reviews. Aust J Physiother 2005;51(2):71-85.

15. Maltais F, Hershfield E, Stubbing D, Wijkstra P, Hatzoglou A, Loveridge $\mathrm{B}$, et al. Exercise training in patients with COPD. In: Bourbeau J, Nault D, Borycki E, editors. Comprehensive management of chronic obstructive pulmonary disease. Hamilton, Ontario, Canada: BC Decker; 2002.

16. Ries AL, Bauldoff GS, Carlin BW, Casaburi R, Emery CF, Mahler DA, et al. Pulmonary rehabilitation: joint ACCP/AACVPR evidencebased clinical practice guidelines. Chest 2007;131(5):4S-42S. 


\section{Aerobic Exercise Intensity in Subjects With COPD}

17. Troosters T, Donner C, Schols A, Decramer M. Rehabilitation in chronic obstructive pulmonary disease. European Respiratory Monograph. Wakefield, United Kingdom: European Respiratory Society; 2006;337-358.

18. Troosters T, Casaburi R, Gosselink R, Decramer M. Pulmonary rehabilitation in chronic obstructive pulmonary disease. Am J Respir Crit Care Med 2005;172(1):19-38.

19. Spruit MA, Singh SJ, Garvey C, ZuWallack R, Nici L, Rochester C, et al. An official American Thoracic Society/European Respiratory Society statement: key concepts and advances in pulmonary rehabilitation. Am J Respir Crit Care Med 2013;188(8):e13-e64.

20. Jones PW, Quirk FH, Baveystock CM. The St George's respiratory questionnaire. Respir Med 1991;85(Suppl B):25-31; discussion 3337.

21. Mahler DA, Weinberg DH, Wells CK, Feinstein AR. The measurement of dyspnea: contents, interobserver agreement, and physiologic correlates of two new clinical indexes. Chest 1984;85(6):751-758.

22. Garrod R, Bestall JC, Paul EA, Wedzicha JA, Jones PW. Development and validation of a standardized measure of activity of daily living in patients with severe COPD: the London chest activity of daily living scale (LCADL). Respir Med 2000;94(6):589-596.

23. ATS Committee on Proficiency Standards for Clinical Pulmonary Function Laboratories. ATS statement: guidelines for the six-minute walk test. Am J Respir Crit Care Med 2002;166(1):111-117.

24. Cazzola M. ATS/ERS Task Force: outcomes for COPD pharmacological trials: from lung function to biomarkers. Eur Respir J 2008; 31(2):416-469.

25. Finch E, Brooks D, Stratford P, Mayo N. Physical rehabilitation outcome measures: a guide to enhanced clinical decision making. Hamilton, Toronto, Ontario, Canada: Lippincott, Williams \& Wilkins; 2002.

26. Witek TJ Jr, Mahler DA. Minimal important difference of the transition dyspnoea index in a multinational clinical trial. Eur Respir J 2003;21(2):267-272.

27. Holland AE, Hill CJ, Rasekaba T, Lee A, Naughton MT, McDonald $\mathrm{CF}$. Updating the minimal important difference for six-minute walk distance in patients with chronic obstructive pulmonary disease. Arch Phys Med Rehabil 2010;91(2):221-225.

28. Laviolette L, Bourbeau J, Bernard S, Lacasse Y, Pepin V, Breton $\mathrm{MJ}$, et al. Assessing the impact of pulmonary rehabilitation on functional status in COPD. Thorax 2008;63(2):115-121.

29. Puente-Maestu L, Villar F, de Miguel J, Stringer WW, Sanz P, Sanz ML, et al. Clinical relevance of constant power exercise duration changes in COPD. Eur Respir J 2009;34(2):340-345.

30. Ferrer M, Villasante C, Alonso J, Sobradillo V, Gabriel R, Vilagut $\mathrm{G}$, et al. Interpretation of quality of life scores from the St George's Respiratory Questionnaire. Eur Respir J 2002;19(3):405-413.

31. American College of Sports Medicine. ACSM's guidelines for exercise testing and prescription, 9th edition. Baltimore, MD: Lippincot Williams \& Wilkins; 2013.

32. Lacasse Y, Martin S, Lasserson TJ, Goldstein RS. Meta-analysis of respiratory rehabilitation in chronic obstructive pulmonary disease: a Cochrane systematic review. Eura Medicophys 2007;43(4):475-485.

33. Puhan MA, Schünemann HJ, Frey M, Scharplatz M, Bachmann LM. How should COPD patients exercise during respiratory rehabilita- tion? Comparison of exercise modalities and intensities to treat skeletal muscle dysfunction. Thorax 2005;60(5):367-375.

34. Bernard S, Whittom F, Leblanc P, Jobin J, Belleau R, Bérubé C, et al. Aerobic and strength training in patients with chronic obstructive pulmonary disease. Am J Respir Crit Care Med 1999;159(3):896901

35. Pereira AM, Santa-Clara H, Pereira E, Simões S, Remédios I, Cardoso J, et al. Impact of combined exercise on chronic obstructive pulmonary patients' state of health. Rev Port Pneumol 2010;16(5): 737-757.

36. Montes de Oca M, Torres SH, González Y, Romero E, Hernández N, Tálamo C. Changes in exercise tolerance, health related quality of life, and peripheral muscle characteristics of chronic obstructive pulmonary disease patients after 6 weeks' training. Arch Bronconeumol 2005;41(8):413-418

37. Dourado VZ, Tanni SE, Antunes LC, Paiva SA, Campana AO, Renno AC, Godoy I. Effect of three exercise programs on patients with chronic obstructive pulmonary disease. Braz J Med Biol Res 2009; 42(3):263-271.

38. Arnardóttir RH, Sörensen S, Ringqvist I, Larsson K. Two different training programmes for patients with COPD: a randomised study with 1-year follow-up. Respir Med 2006;100(1):130-139.

39. Foglio K, Bianchi L, Bruletti G, Porta R, Vitacca M, Balbi B, Ambrosino N. Seven-year time course of lung function, symptoms, healthrelated quality of life, and exercise tolerance in COPD patients undergoing pulmonary rehabilitation programs. Respir Med 2007; 101(9):1961-1970.

40. Normandin EA, McCusker C, Connors M, Vale F, Gerardi D, ZuWallack RL. An evaluation of two approaches to exercise conditioning in pulmonary rehabilitation. Chest 2002;121(4):1085-1091.

41. Rochester CL. Exercise training in chronic obstructive pulmonary disease. J Rehabil Res Dev 2003;40(5 Suppl 2):59-80.

42. Casaburi R, Patessio A, Ioli F, Zanaboni S, Donner CF, Wasserman $\mathrm{K}$. Reductions in exercise lactic-acidosis and ventilation as a result of exercise training in patients with obstructive lung-disease. Am Rev Respir Dis 1991;143(1):9-18.

43. Maltais F, LeBlanc P, Jobin J, Bérubé C, Bruneau J, Carrier L, et al. Intensity of training and physiologic adaptation in patients with chronic obstructive pulmonary disease. Am J Respir Crit Care Med 1997;155(2):555-561.

44. Puente-Maestu L, Sánz ML, Sánz P, Cubillo JM, Mayol J, Casaburi R. Comparison of effects of supervised versus self-monitored training programmes in patients with chronic obstructive pulmonary disease. Eur Respir J 2000;15(3):517-525.

45. Gimenez M, Servera E, Vergara P, Bach JR, Polu JM. Endurance training in patients with chronic obstructive pulmonary disease: a comparison of high versus moderate intensity. Arch Phys Med Rehabil 2000;81(1):102-109.

46. Hsieh MJ, Lan CC, Chen NH, Huang CC, Wu YK, Cho HY, Tsai $\mathrm{YH}$. Effects of high-intensity exercise training in a pulmonary rehabilitation programme for patients with chronic obstructive pulmonary disease. Respirology 2007;12(3):381-388.

47. Butcher SJ, Jones RL. The impact of exercise training intensity on change in physiological function in patients with chronic obstructive pulmonary disease. Sports Med 2006;36(4):307-325. 